\title{
Cativos do Protocolo de Palermo
}

\author{
José Carlos Sebe Bom Meihy *
}

\section{Retraços históricos}

Tendencialmente há esforços em demonstrar a perenidade dos deslocamentos demográficos como fenômeno vital para o entendimento da dinâmica histórica. $O$ sair dos espaços originais, a busca de outros lugares, pelos mais diferentes motivos, tem sido explicado como variante de tradições intrínsecas à condição humana, há milênios. E não faltam exemplos flagrados em tradições bíblicas como a expulsão de Adão e Eva do Paraíso, o Êxodo, a Fuga da Sagrada Família para o Egito. Na mesma toada, desde Homero, na llíada, são registradas situações que tipificam o deslocamento de pessoas de uma plaga à outra, como movimento incessante, próprio de atividades da vida social planetária. Migração e submissão humanas, procura de lócus ideal para viver ou se refugiar, pois, seriam práticas inseparáveis dos processos de transformação do mundo, situações que acompanham a ascendente curva de progressão populacional e as crescentes organizações de produção e consumo destinadas a atender as demandas das sociedades. Então, desde as chamadas antigas civilizações - da Mesopotâmia à Roma - e mais modernamente os Impérios Ultramarinos, todos os sistemas admitiram sempre regimes de sujeição humana, usando artimanhas que se explicam adaptadas aos espaços e tempos, aos plurais códigos de convivência e moralidade governamental. Hoje, consideradas as movimentações humanas e os avanços facilitadores das mobilidades, é difícil falar de fronteiras, sejam pessoais, nacionais ou de culturas. A própria democracia se redefine como convívio com a diferença, orientado pela multiplicidade de regras acordadas por diversos segmentos (BOBBIO, 2000, p. 13).

* Coordenador do Núcleo de Estudos em História Oral da USP (NEHO-USP) e Prof. do Programa de Pós-Graduação Stricto Sensu em Letras e Ciências Humanas da UNIGRANRIO. 
Assumindo diferentes justificativas, de acordo com as transformações localizadas historicamente, têm sido formuladas razões aptas a explicar os deslocamentos e a exploração do "outro", do mais fraco e vulnerável, compelido a trabalhos, serviços e práticas ${ }^{1}$. Foi assim que, se valendo da violência exploratória, o chamado "regime escravocrata" se fez, desde tempos idos, em suas variantes, para sustentar dominações e montagem de comércio que justificava o lucro ou a exploração em escala progressiva ampla e globalizante (BONJOVANI, 2004). Segundo a determinação dessas práticas, diferentes frações expressaram fundamentos imprimindo em seus contextos culturais diversos enredos religiosos, filosóficos e éticos. E nem faltaram bases teológicas para redimir explorações dos próprios seres humanos (MARQUESE, 2004). O delineamento evolutivo da relação de poder e domínio de uns sobre outros, portanto, tem na continuidade o chão comum, ainda que sujeita às adaptações convenientes em ambientes e andamentos culturais distintos.

Grosso modo, a contrapelo do persistente fundamento dos negócios inerentes à movimentação, se reconhece que desde o século XVIII se deram empenhos capazes de regulamentar tais métodos com o fito de extingui-los, ou pelo menos cerceá-los, segundo as orientações dos tempos e governos. Os primeiros acordos entre Estados, sobre tal matéria, começaram na França e Inglaterra, quando, em 1814 foi celebrado o Tratado de Paris atento a limitar o tráfico negreiro. Esse esforço evoluiu lentamente, até que em 1926 fosse acordada uma Convenção firmada pela Sociedade das Nações, que colocava em litígio os preceitos sobre processos e tipos de escravidão que vigoravam até aquele momento. Tal tendência evolveu e teve ponto alto em 1956, quando a Convenção de Genebra firmou propósitos destinados a conter práticas variadas, que perduram em versões contemporâneas, próximas do modo escravagista ${ }^{2}$. Desde logo, a mulher tornou-se objeto de questão e sua vulnerabilidade deu ensejo, em 1904, ao Acordo para a Repressão do Tráfico de Mulheres Brancas. Hoje criticado por se limitar a um gênero - feminino - e a um segmento único mulheres brancas - esse artifício legal, contudo, alçou a condição de Convenção aderida por vários Estados signatários.

\section{O Fundamento do Protocolo de Palermo}

Em 2000, tal processo evoluiu em nível internacional, gerando dois atos atentos a combater o tráfico internacional de pessoas, a saber: 1- o Protocolo para Prevenir, Suprimir e Punir o Tráfico de Pessoas, Especialmente Mulheres e Crianças, e, 2- o Protocolo contra o Contrabando de Imigrantes por Terra, Mar ou Ar. Este, mais conhecido como Protocolo de Palermo, lavrado sob os auspícios da Convenção da ONU Contra o Crime Organizado Transnacional, tornou-se o documento jurídico mestre sob o patrocínio da ONU, gerando vida a um Comitê Intergovernamental, destinado a elaborar princípios afeitos ao tratado do tráfico de pessoas, em geral, em particular de mulheres e crianças (CASTILHO, 2008). O Brasil, desde 2004 é signatário do Protocolo de Palermo legitimado pelo Decreto $\mathrm{n}$ - 5.017, promulgado no dia 12 de março daquele ano ${ }^{3}$. Segundo o texto 
expresso pelo Ministério da Justiça do Brasil, "o tráfico de pessoas é um fenômeno complexo e multidimensional, englobando diversas práticas criminosas e de violação aos direitos humanos".

Sem dúvida, o conhecido Protocolo de Palermo é um instrumento legal valioso, de alcance internacional, ferramenta de alta relevância em favor da defesa dos cidadãos em geral, em particular no que tange aos direitos humanos de pessoas traficadas, vítimas ou ofendidas em sua liberdade ou autonomia de ir e vir, de estar ou ficar ${ }^{4}$. Consagrando a validade desta ferramenta amplamente aceita, no entanto, cabe sobressair outros aspectos que podem dialogar com a eficácia desse recurso legal indo, inclusive, além de seus efeitos de controle e combate à formidável movimentação do Tráfico de Pessoas (TP) em escala planetária. Há valiosas contribuições atentas à crítica de alguns fundamentos do Protocolo de Palermo e cabe considerar tais assertivas como parte da melhoria do texto e da prática desse instrumento jurídico. Tudo, claro, em favor dos direitos humanos e da dignidade cidadã, contra a exploração de pessoas e em proteção à sociedade em geral. Assim, salientadas suas relevâncias, questionam-se seus efeitos indiretos e objetivos na vida de atingidos, pessoas que, tantas vezes, não se veem abrigadas nesta sombra legal. Dizendo de outra maneira, o Protocolo, na maioria dos casos, mais se parece com discurso de oficialidades policiais, mero libelo de Direito Internacional, do que propriamente um fator sensível em prol dos desprotegidos, ofendidos, vitimados e em defesa da sociedade como um todo.

\section{Fermentos críticos}

Na esfera exegética, vários autores abordam a pertinência do Protocolo, indicando inclusive uma via, contramão, na anuência fácil, imediata e generalizante dos supostos positivos, firmados na Convenção. A grande virtude do texto é legislativa, i.e., colocar em letra viva regras capazes de atuar como parâmetros contra abusos que resultam na exploração humana. Exatamente por isto é que, paradoxalmente, despontam reparos a serem feitos no documento matriz e que sugerem detalhamentos circunstanciais, atenuantes. A leitura do Protocolo, por exemplo, evidencia que sua preocupação precípua remete a uma tríade calcada no recrutamento, transporte e exploração de pessoas. Sob esses itens, no entanto, se escondem particularidades, nuances das vidas, dos segmentos subjugados. Acontece também o estabelecimento de um poder que se arvora tutelar e potente para exercer atividade, até mesmo, acima das vontades dos ofendidos e vitimados. Tudo decorre do documento da Convenção que enquadra procedimento segundo:

O recrutamento, o transporte, a transferência, o alojamento ou o acolhimento de pessoas, recorrendo à ameaça ou uso da força ou a outras formas de coação, ao rapto, à fraude, ao engano, ao abuso de autoridade ou à situação de vulnerabilidade ou à entrega ou aceitação de pagamentos 
ou benefícios para obter o consentimento de uma pessoa que tenha autoridade sobre outra para fins de exploração ${ }^{5}$.

Ao tratar o recrutamento como ato inaugural, o Protocolo não se preocupa com especificidades e tipifica o crime a partir da submissão da pessoa traficada em qualquer situação, independentemente da própria anuência ou consentimento tácito ou implícito. Tudo é como se houvesse apenas luz e sombra, claro ou escuro, e isto equivale dizer que, sem graduações, a lei se torna perversa e, em certa medida, submete os atingidos anulando drasticamente suas vontades. Dessa maneira, o que se tutela é criminalização da conduta no que tange à liberdade dos cidadãos prejudicados. Então, pouco ou nada interessam os detalhes ou motivações enlaçados na relação entre ofendidos e vítimas, seus algozes e as instituições de amparo aos submetidos. Ao se limitar ao dizer conceitual recrutamento, tudo fica teórico e vago, abstrato e independente das realidades de cada caso. $O$ efeito prático, pois, se mostra arbitrário e legalista, pouco humanizado ou sensível às razões subjetivas de cada caso, ainda que a proposta seja anunciada em nome dos direitos humanos. Tal postura se porta autoritária e com sérias consequências sobre a vontade da parte prejudicada que se torna, automaticamente, agente passivo da ação controladora exercida por órgãos muito distantes de suas realidades. Assim, pouco importa a motivação ou os motores socioculturais e econômicos que impulsionaram o movimento de adesão dos prejudicados. E, questiona-se, sem a efetiva atuação dos atingidos, como pensar em reintegração ou protagonismo no processo?

Outro aspecto tangível remete ao entendimento de exploração, implicada, segundo o texto do Protocolo, tanto em limitação da liberdade sexual, de trabalho como do direito legítimo de imigrar ou de ir e vir. Da simplificação do uso do termo exploração depreende-se a aproximação equivocada do marco escravidão, como se fosse, na modernidade, a perpetuação de práticas cabíveis em outros contextos históricos e modos de produção. $O$ uso desmedido do termo escravidão sugere um apelo dramático, mas pouco condizente com o mundo do trabalho que, no contexto do capitalismo, anima a exploração de pessoas. Daí, por exemplo, reclama-se da continuidade do artigo $3^{\circ}$, na alínea "a" onde se lê in verbis:

A exploração incluirá, no mínimo, a exploração da prostituição de outrem ou outras formas de exploração sexual, o trabalho ou serviços forçados, escravatura ou práticas similares à escravatura, a servidão ou a remoção de órgãos.

Negligenciado o teor do termo escravidão, destituído de sua potência historicamente estabelecida, a palavra aniquila a atuação das vítimas ou ofendidos e os reduz à condição escrava como se não houvesse condição alguma de busca de autonomia. Tudo vira mercadoria, material manipulável. E neste cenário, a lei vira o condão capaz de libertar os sujeitados. Paternalismo à parte, cabe contestar a suposta passividade dos sujeitados. O tema do consentimento, 
assim, passa a se situar na planura do termo e desta forma não se leva em conta situações de anuência, desejos, determinação, dos implicados e nem mesmo suas estratégias de mudanças de status social ou até de sobrevivência.

Em pesquisas de campo, é comum se notar que muitas das pessoas ofendidas ou vitimadas pelo tráfico não se reconhecem como tal, posto que em tantos casos elas mesmas concorrem para facilitações do ato condenado. Sem conhecimento das histórias de vida, contudo, apartados da singularidade de cada caso, torna-se impossível avaliar as circunstâncias das vulnerabilidades. Com certeza, o ato mais cruel do texto da Convenção remete à redução do prejudicado à sua "objetificação", como se fosse ser inconsistente, incapaz de zelar por si em todas as dimensões. Pode-se dizer que há a consagração de um Darwinismo Social aplicado à relação moderna de trabalho. Recrudesce, pois, um dos eixos mais polêmicos do Protocolo que não toma em causa a pessoa ou sujeito que justifica a atitude internacionalista do preceito legal. Pior, torna-os iguais em qualquer situação ou quadrante da Terra. Como se fosse mero aposto, a vítima ou ofendido se volve paciente, e a lei, mais que ignorar a vontade da parte já prejudicada, anula-a. Isto explica a obsessão pelos números estatísticos e mais do que isto, a inexplicável falta de voz dos protagonistas principais. Na superfície o que brota sempre é o papel da Polícia que se mostra redentora e assim artífice da justiça. Fica nessa relação consagrada a ordem: bandidos $x$ mocinhos $x$ vítimas inocentes $\mathrm{e}$ indefesas. Superpoderes $\mathrm{x}$ migalhas humanas.

\section{0 fermento brasileiro}

No Brasil, tal crítica também é exercida com ênfase e, além das reclamações generalizantes atentas ao consentimento, vários autores tecem comentários pertinentes, como faz Daniela Muscari Scacchetti, ao se referir à fusão, nos termos do Protocolo, de tráfico, migração/imigração, e contrabando de pessoas. Levando em monta a discussão sobre o transporte, fica evidente que as regras do Protocolo devem implicar principalmente distinções entre tráfico e o contrabando de pessoas (SCACCHETTI, 2011). No caso do contrabando, a participação efetiva do interessado o faz também cúmplice e isto é crime. Nos itens mencionados - recrutamento, transporte e exploração - deve ficar à luz que a relação implica o estabelecimento de uma repulsão, ato excludente, dos traficados que apenas figuram como motivo da formidável ação policial tida como heroica. Avesso disto, garante-se força aos poderes dos agentes instituídos que se tornam entidades magnânimas ou salvacionistas. Resultado: a "vitimização" dos ofendidos os converte em seres sem vozes, inativos, desgraçados e sem qualquer protagonismo que não sua ignorância, inocência ou deliberação consciente postos a público. Neste sentido, ressalva-se detalhe do texto de uma Cartilha de apoio e esclarecimento aos traficados, intitulada "Escravo, nem pensar!" da Repórter Brasil, feita com apoio do Ministério Público do Trabalho em Mato Grosso, que diz didaticamente, referindo-se em particular às vítimas: 
Muitas organizações que lutam pelos direitos das mulheres não gostam da palavra vítima. É fácil entender o motivo: vítima pode passar a ideia de que a mulher é fraca, uma coitadinha. Essas organizações sugerem a expressão "pessoas afetadas pelo tráfico".

E prossegue:

Usamos vítima, nesta cartilha, porque são mulheres (e homens) que tiveram seus direitos violados. Mas não queremos negar (pelo contrário!) a condição de cidadã e cidadão, de sujeito político.

Em palavras claras a Cartilha retraça o perfil dessas pessoas, da seguinte maneira:

\begin{abstract}
As vítimas do tráfico de pessoas têm um perfil comum, apesar das formas de exploração serem diferentes. Em geral, são jovens, de baixa renda, com pouca escolaridade, que começaram a trabalhar cedo e migram porque não têm condições de sobrevivência digna em seus lugares de origem. Por isto, costuma-se dizer que acabaram traficadas porque estavam vulneráveis, ou seja, em uma situação social e econômica que as privou de alternativas concretas de trabalho ${ }^{6}$.
\end{abstract}

Nota-se, claramente, que a legislação brasileira e diversas instituições de apoio aos envolvidos no tráfico "complexibilizam" os termos do Protocolo e propõem leituras mais drásticas. Na lógica do protecionismo ilimitado, por exemplo, a Política Nacional de Enfrentamento ao Tráfico de Pessoas Brasileira, amplia ainda mais a proteção aos afetados, desconsiderando sua participação em qualquer nível. Mesmo ferindo o livre arbítrio e transferindo para os poderes constituídos as ações tuteladoras, extrapola-se a intenção do Protocolo ${ }^{7}$. Com isto se conclui que a evolução dos preceitos legais contidos na Convenção consegue ir além do próprio Protocolo, reduzindo em nome de um artifício jurídico ainda mais a capacidade de atuação dos atingidos. Sob esta linha de raciocínio, o texto da Política Nacional de Enfrentamento consegue ser mais realista que o rei.

Ainda em termos da problemática conceitual, Adriana Piscitelli aprofunda o exame de algumas definições que se mostram universais ou sem grande precisão quando vistas sob a luz de nossa prática cultural. No exame das significações, a diferenciação ou a nuance entre o que é "ajuda", "apoio", individual ou de grupo, e a caracterização de uma "máfia" ou de articulações do tráfico internacional se torna eticamente fundamental. Os exames das histórias pessoais de pessoas que vão a outros países sob a conduta exploratória, não têm obrigatoriamente que se vincular ao tráfico. São suas as seguintes palavras ao concluir relevante texto sobre a matéria: 
Mostrei, ainda, como a existência de diferentes definições de tráfico de pessoas e a falta de clareza conceitual dos termos que contribuem para delimitar a problemática, principalmente a noção de exploração, colocam sérios problemas para a produção de conhecimento também no Brasil.

E conclui

Nesse âmbito se produz a fusão entre crime e violação dos direitos humanos, às vezes utilizada instrumentalmente para reprimir a migração não documentada e também para combater a prostituição ${ }^{8}$.

De certa forma, ao assumir postura de regra internacional, o Protocolo consagra a caça aos traficantes como uma empresa, mas despreza a capacidade de entendimento dos traficados. Mais: cria uma sensação de justiça e eficiência que contrasta com os números sempre crescentes desse comércio de gente. Nesta linha, Thaddeus Gregory Blanchette e Ana Paula da Silva ressaltam que é preciso mudanças, pois:

Calcada em definições contraditórias do crime, a luta contra o tráfico de pessoas movimenta-se em nome da "abolição da escravidão moderna". Neste ambiente francamente moralista, o movimento antitráfico no Brasil se sustenta na repetição de números inventados e declarações apocalípticas, sem base epistemológica alguma? .

Ao falar de números e de efeitos sensacionalistas, deve-se levar em conta a exiguidade dos resultados das ações decorrentes da aplicação do Protocolo. De acordo com a OIT (Organização Internacional do Trabalho), uma média de 4 milhões de pessoas entram na rota do tráfico, anualmente, no mundo todo, sendo que desse total cerca de 700 mil são mulheres e crianças que se inscrevem no circuito do tráfico internacional destinado à exploração sexual. De maneira desastrosa, o Brasil se mostra como país líder no número de mulheres usadas para fins de exploração sexual e assim se fixa o número segundo dados da Fundação Internacional Helsinque de Direitos Humanos:

Do Brasil, o número de mulheres exploradas sexualmente na União Europeia, chega a aproximadamente 75 mil ou $15 \%$ deste total e segundo dados da Polícia Federal Portuguesa, a cada dez prostitutas em Portugal, nove são brasileiras ${ }^{10}$. 
Seja pelos números de participantes das redes internacionais de exploração do trabalho e/ou da atividade sexual, ou pelos argumentos críticos já apresentados, o Brasil precisa ter papel protagonista no concerto da argumentação que toma o Protocolo como base de ação sobre a matéria.

\title{
O Brasil e o Protocolo
}

Mas por que os brasileiros, pergunta-se? A pluralidade das respostas demanda considerar fatores agravantes de uma tendência crescente. Como não basta constatar os números, qualquer análise crítica do teor do Protocolo exige contextualização. No caso específico do Brasil, dois fatores chamam atenção: o apagamento da participação das vítimas e ofendidos e a reputação sexual de nossos patrícios. Além de causas imediatas, é necessário considerar as motivações remotas, históricas que abrangem desde trajetos historicamente delineados até as propagandas turísticas governamentais. Mais do que isso, porém, se deve levar em conta as tensões acumuladas que incidem nas escolhas dos prejudicados. Tudo é de muito difícil avaliação e demanda inclusive elaboração que mexa com números. É nesta linha que se destaca o trabalho de Siddharth Kara, especialista em tráfico humano, por exemplo, ao mostrar que o motor da movimentação de pessoas que trabalham com sexo se dá pelo atrativo econômico que, aliás, se situa entre os negócios de maior lucratividade do mundo. Então, atento a esta orientação, o economista, banqueiro, professor de Harvad, tratou de proceder um modelo ou fórmula econômica capaz de estimar custos da surpreendente movimentação no valor total de mais de US\$ 35 bilhões de lucro anual permitido pela escravidão sexual. Neste panorama, depois de proceder a mais de 400 entrevistas feitas em 14 países, Kara concebeu um padrão para avaliar o total de explorados no mundo, montante este que chegaria a 29 milhões, sendo 1,3 milhão explorados sexualmente. $O$ impressionante é que mesmo representando este número somente $4 \%$ do montante geral, tal negócio gera $40 \%$ dos lucros. $\mathrm{E}$ conclui que a cada ano, cerca de 500 mil pessoas são traficadas. Em entrevista sobre seu livro Tráfico Sexual, o autor, Kara, diz que:

\begin{abstract}
Escravidão é obviamente uma violação dos direitos humanos, mas é também fundamentalmente um crime econômico, que procura maximizar os lucros ao diminuir os custos do trabalho. Para entender, analisar e combater a escravidão moderna, até agora não tinha sido feito um estudo econômico do problema, o que resulta em políticas falhas e desordenadas ${ }^{11}$.
\end{abstract}

Sobremaneira, interessa o destaque dado ao desencontro de políticas públicas. É exatamente para ressaltar as "políticas falhas e desordenadas" que Kara demonstra o mecanismo usado para justificar o critério de preço das 
pessoas traficadas e, assim, referindo-se ao Brasil, diz que, em comparação com outros 12 países, o Brasil lidera no preço de compra das prostitutas em mercados importantes como o italiano.

Segundo tabela, a mulher brasileira é vendida, em média, por 5.000 [euros] (cerca de $\mathrm{R} \$ 15 \mathrm{mil}$ ), e seu "ato sexual comercial" custa em torno de 40 [euros]. O país aparece à frente de Rússia (3.500 pela mulher, 30 pela relação sexual), Romênia ( 2.000 e 20 , respectivamente) e de mais nove países, a maioria do Leste Europeu ${ }^{12}$.

De acordo com este suposto, as brasileiras se tornam vítimas de um engenho mais sofisticado, posto que nossas mulheres e homens experimentam antes uma espécie de estágio que seleciona e prepara as pessoas. O fato de ser comum no Brasil os traficados passarem por experiências em grandes centros, facilita a acomodação em lócus internacionais, então explica o autor:

O processo em duas etapas - tráfico interno seguido de tráfico internacional - é um desenvolvimento novo, baseado num modelo de negócio mais sofisticado. As escravas ficam menos resistentes, então se avalia quais serão mais facilmente exploradas no exterior - com menos chances de escapar. [E complementa mostrando que] outras são traficadas internacionalmente desde o início ${ }^{13}$.

De certa maneira depreende-se que há uma reputação firmada sobre as brasileiras e que, ainda que sutilmente, formamos uma espécie de prática de preparo à prostituição internacional. Fato concreto, porém, é a reputação das mulheres e homens brasileiros que se destinam, por um ou outro motivo, à atividade sexual no exterior (PISCITELLI, 2013).

Em uma série de entrevistas com prostitutas e prostitutos brasileiros, em seis países europeus e nos Estados Unidos, numa relação de mais de setenta gravações longas, colhidas em três momentos diferentes, no espaço de quatro anos, duas situações chamam a atenção: o desconhecimento absoluto das vítimas sobre o significado e impacto do Protocolo de Palermo, e, o paternalismo inerente ao teor aplicativo do Protocolo. Ilustro o caso com passagem registrada em situação de tráfico de rapazes de um estado brasileiro, nordestino, onde a grande imprensa divulgou - inclusive em escala mundial - o escândalo de jovens recrutados para trabalho, mas empregados na prostituição na Espanha ${ }^{14}$. Detalhemos as situações:

Miro, modesto jovem de 24 anos, de pouca escolaridade e muito pobre, casado, pai de dois filhos, soube por anúncios de jornais de ampla circulação, que uma empresa oferecia oportunidade de trabalho para moços "fortes e dispostos a ganhar algum dinheiro com rapidez, indo para serviços na Europa". 
Frente às necessidades familiares prementes, o rapaz deixou para trás tudo que tinha. Vendeu sua aliança, a bicicleta, roupas e o que mais pôde. Tudo para pagar a passagem e os documentos. Ao chegar na Espanha, se viu enganado, premido a entrar na prostituição e, para tanto, se viu viciado no uso de popper, droga fornecida pelos próprios agenciadores. Aliciado para trabalho em saunas, o jovem teve seus documentos confiscados e, sob constantes ameaças, se viu forçado a práticas estranhas à sua vontade. A complexa adaptação ao regime de exploração - sempre feita mediante grave ameaça e constrangimento de força física e psicológica - levou-o a vivências extremas e desesperadoras. Depois de meses de exploração, sem contatos fora do ambiente de prostituição, foi socorrido por alguém de uma ONG que o levou às reuniões dos Narcóticos Anônimos que, por sua ação positiva, o retirou das malhas do tráfico. Para surpresa geral, porém, o jovem não quer voltar, alegando vergonha e incapacidade de reinserção no próprio meio. Depois de ouvir detalhes dolorosos de suas peripécias, pergunteiIhe se conhecia o Protocolo de Palermo e, de maneira natural, ouvi: "Protocolo do Palermo? Não! Não conheço ninguém com este nome 'Protocolo'. Por que, ele é um palerma?" O que parece ser uma piada, não deixa espaço para a lástima, pois a distância entre o drama do ofendido e a inoperância legal é lastimável. Em conversa com as pessoas que o socorreram e novamente questionando sobre o Protocolo de Palermo ouvi "isto é para aquela minoria que acaba servindo de exemplo para justificar a ação policial". E de maneira contundente tive como resposta outra pergunta "quantas pessoas são beneficiadas por esta máquina"? Mais, "o Protocolo é importante quando salva, mas na maioria das vezes é mais um espetáculo pirotécnico do que uma lei que beneficia".

\section{Conclusão}

É a hora de reconhecer, sim, os valores implícitos no Protocolo de Palermo. Lei digna esta, mas carente de reparos importantes. Como estão formulados os supostos daquele artifício jurídico internacional, temos a sagração do poder policial instituído e a ratificação do aniquilamento dos vitimados e ofendidos. Estes, parece, são seres inativos, sem condições de reação, dignos mesmo da concepção de vítimas. Assim mostrados, anulados em suas histórias pessoais, viram meras peças de um jogo complexo e feito pelos outros, delegados de autoridades insensíveis às miudezas do particular.

A proposta que se levanta convida supor a valorização dos seres penalizados com o tráfico e reconhecer neles atitudes capazes de fermentar reações que os levem em conta. Mesmo sendo enganados, humilhados até o limite máximo, aprendem, amadurecem, têm o que dizer. Não são seres aniquilados, incapacitados de reação. Na lógica da ajuda necessária, cabe estabelecer meios que qualifiquem tais pessoas e que não cassem sua dignidade e expressão participativa. Não há como negar maturações e aprendizados aos que padecem tais explorações. Anulá-los significaria reduzi-los duplamente à condição de vítimas sociais. No caso específico de Miro, pela eficácia das leis, dado que ele mesmo se esforçou para ser traficado, mesmo sem saber, sua condição de 
cúmplice o levaria à criminalização. O conhecimento de detalhes de sua saga para sustentar a família e os sacrifícios feitos em favor da busca de melhores condições o coloca como uma espécie de herói de sua situação. E nem bastaria ser sombreado pelos favores do Protocolo de Palermo que ele sequer conhece, ou ouviu falar. Por fim, cabe sopesar a questão da reinscrição social em seu meio. No momento, sem assistência psicológica, sem acompanhamento, ele simplesmente não quer voltar. O que, neste caso, valeria o Protocolo?

\section{Notas}

1 - Sobre o tema leia-se A história da escravidão, de Oliver Patre-Grenouilleau (2009).

2 - Diz a Secção II, sobre "tráfico de escravos", no artigo $3^{\circ}, 1$. "O acto de transportar ou de tentar transportar escravos de um país a outro, qualquer que seja o meio de transporte utilizado, ou a cumplicidade no referido acto, constituirá delito à face da lei dos Estados Partes na Convenção, e as pessoas consideradas culpadas de tal delito serão objecto de penas muito severas... 3. Os Estados Partes na Convenção procederão à permuta de informações, a fim de assegurar a coordenação prática das medidas por eles tomadas para combater o tráfico de escravos, e comunicar-se-ão todos os casos de tráfico de escravos, bem como toda e qualquer tentativa nesse sentido de que tenham conhecimento".

3 - Cf. <http://www.planalto.gov.br/ccivil_03/_ato2004-2006/2004/decreto/d5017.htm>. Acesso em 28 nov. 2013.

4 - Convém distinguir os conceitos, pois "vítima" se refere aos delitos contra a pessoa, enquanto "ofensa" ou "ofendido" diz respeito aos crimes contra a honra e costumes. Sobre o assunto leiase A autocolocação da vítima em risco, de Alessandra Orcesi Pedro Greco (2004, p. 17-18).

5 - Protocolo Complementar à Convenção das Nações Unidas contra o Crime Organizado Transnacional Relativo à Prevenção, Repressão e Punição do Tráfico de Pessoas, em Especial Mulheres e Crianças, promulgado pelo Decreto no 5.017 de 12 de março de 2004.

6 - "Escravo, nem pensar!" Repórter Brasil, Ministério Público do Trabalho/MT. Disponível em: <http://www.escravonempensar.org.br/upfilesfolder/materiais/arquivos/cartilha_trafico_ spread_WEB.pdf>. Acesso em: 21 fev. 2014.

7 - Artigo 2으, § 70 da Política Nacional de Enfrentamento ao Tráfico de Pessoas, aprovada pelo Decreto no 5.948 , de 26/10/2006.

8 - Disponível em: <http://www.scielo.br/scielo.php?pid=s0104-83332008000200003\&script =sci_arttext>. Acesso em: 21 fev. 2014.

9 - Sobre o assunto leia-se o artigo $O$ mito de Maria, uma traficada exemplar: confrontando leituras mitológicas do tráfico com as experiências de migrantes brasileiros, trabalhadores do sexo, de Thaddeus Gregory Blanchette e Ana Paula da Silva. Disponível em: <http://www. csem.org.br/remhu/index.php/remhu/article/view/278>. Acesso em: 13 maio 2013.

10 - Dados da Fundação Helsinque de Direitos Humanos. In: Danielle de Carvalho Vallim. Um estudo sobre o tráfico de mulheres para exploração sexual: o encontro entre Estado e ONG's na construção de uma política pública. Disponível em: <http://www.uff.br/dcp/wp content/ uploads/2011/10/Disserta\%C3\%A7\%C3\%A3o-de-2010-Danielle-de-Carvalho-Vallim.pdf>. Acesso em: 21 fev. 2014.

11 - Disponível em: <http://www.bresserpereira.org.br/Terceiros/2009/09.02.Obalancoda prostituicao.pdf $>$. Acesso em: 28 nov. 2013.

12 - Ibidem.

13 - Ibidem.

14-Sobreogrupodetraficadosleia-se<http://www.estadao.com.br/noticias/cidades, espanhadesarticula-rede-de-prostituicao-que-explorava-homens-brasileiros,603181,0.htm>. Acesso em: 28 nov. 2013. 


\title{
Referências
}

BOBBIO, Norberto. O futuro da democracia. São Paulo: Paz e Terra, 2000, p. 13.

BONJOVANI, Mariane Strake. Tráfico Internacional de Seres Humanos. São Paulo: Ed. Damásio de Jesus, Série Perspectivas Jurídicas, 2004.

CASTILHO, Ela Wiecko V. Tráfico de pessoas: da Convenção de Genebra ao Protocolo de Palermo. In: Brasil. Secretaria Nacional de Justiça. Política nacional de enfrentamento ao tráfico de pessoas. Brasília-DF: SNJ, 2008.

GRECO, Alessandra Orcesi Pedro. A autocolocação da vítima em risco. São Paulo: Revista dos Tribunais, 2004. p. 17-18.

KARA, Siddharth. Sex Trafficking: Inside the Business of Modern Slavery. Columbia University Press, 2009.

MARQUESE, Rafael de Bivar. Feitores do corpo, missionários da mente. São Paulo: Companhia das Letras, 2004.

PATRE-GRENOUILLEAU , Oliver. A história da escravidão. Rio de Janeiro: Boitempo, 2009.

PISCITELLI, Adriana. Trânsitos: Brasileiras nos mercados transnacionais do sexo. In: Coleção: Sexualidade, Gênero e Sociedade, Rio de Janeiro: CLAM/EdUERJ, 2013.

SCACCHETTI, Daniela Muscari. O tráfico de pessoas e o Protocolo de Palermo sob a ótica de Direitos Humanos. In: Revista Internacional de Direito e Cidadania, n. 11, p. 25-38, out. 2011.

\section{RESUMO}

O Protocolo de Palermo é um dos documentos mais importantes sobre o tráfico de pessoas, tema de grande importância no mundo globalizado. Com adesão de quase todos os países do mundo, o Protocolo, ainda que expresse avanços, guarda problemas que se refletem exatamente nos grupos que pretende proteger. A crítica maior a este documento decorre da distância entre os agentes emissores e as pessoas tratadas como "vítimas". O tom oficial do enunciado do texto, além de submeter os implicados como "vítimas", promove o aparato dos Estados como entidade salvadora única. A consequência mais evidente deste documento é a redução das "vítimas" como incapazes de gerenciar a própria vida. Desdobramento natural disto é a falta de sintonia entre as Polícias Federais e os envolvidos que padecem nas malhas do tráfico.

Palavras-chave: tráfico humano; Protocolo de Palermo; mundo globalizado.

\begin{abstract}
The Palermo Protocol is one of the most important documents about human trafficking, a matter of great importance in a globalized world. Signed by almost all countries, the Protocol is a step forward even if it still has problems that reflect upon the groups it intends to protect. The strongest criticism against this document is the distance between the State and the persons, treated as "victims". The official tone of the text, besides victimizing people, promotes the State as the only savior. The most evident consequence of this document is the reduction of people to the condition of "victims", seen as incapable of managing their own lives. A natural development of this is the lack of connection between Federal Police units and the trafficked, that suffer even more in the hands of the traffic.
\end{abstract}

Keywords: human trafficking; Palermo Protocol; globalized world. 